\title{
MACHUCABILIDADE: A FALTA DE DESIGN DE USABILIDADE PODE MACHUCAR O USUÁRIO
}

\author{
Moisés Henrique Ramos Pereira ${ }^{1}$ \\ Ana Paula de Carvalho ${ }^{2}$ \\ Francielly Morais Rodrigues da $\operatorname{Costa}^{3}$ \\ Cayley Guimarães ${ }^{4}$ - Orientador \\ 1'moiseshrp@gmail.com; ${ }^{2}$ anapaulacdv2000@gmail.com; ${ }^{3}$ franciellycrier@gmail.com; \\ ${ }^{4}$ profcayley@yahoo.com.br \\ Curso de Ciência da Computação - Uni-BH (www.unibh.br)
}

\begin{abstract}
Resumo - A Sociedade da Informação e do Conhecimento traz consigo um aumento no número dos sistemas de informação e dos objetos com alta complexidade de uso. Cabe aos designers construí-los de forma a ajudar o usuário a realizar a tarefa desejada, sem se machucar. Contudo, observa-se um elevado número de acidentes provocados pela falta de usabilidade. Este estudo analisa sete destes casos, indicando teorias para as respectivas causas e sugerindo algumas soluções para os problemas discutidos a fim de promover uma reflexão sobre a falta de usabilidade dos novos sistemas.
\end{abstract}

Palavras-chave - usabilidade, design, machucar.

Abstract - The Information Society and Knowledge brings with it an increase in the number of information systems and objects with high complexity in use. It is up to designers built them to help the user to perform the desired task, without getting hurt. However, there is a high number of accidents caused by lack of usability. This study examines these seven cases, indicating theories to their causes and suggesting some solutions to the problems discussed in order to promote a reflection on the lack of usability of the new systems.

Keywords - usability, design, hurt.

\section{INTRODUÇÃo}

$\mathrm{Na}$ sociedade do conhecimento, os sistemas de informação, e o design de usabilidade destas ferramentas, permeiam os objetos do dia-a-dia, com complexidade crescente. Segundo Norman (2008), à medida que as funções aumentam, aumenta também a necessidade de aquisição destes novos designs: desejam-se sistemas que apresentem muitas funções, mas que não sejam confusos. Principalmente, objetos que realizem a tarefa a que se propõem, com usabilidade.
Usabilidade, segundo Krug (2006) significa "assegurar-se que algo funcione bem; que uma pessoa com habilidade e experiência comuns (ou até menos) possa usar algo - seja um web site, um caça a jato ou uma porta giratória - para seu propósito desejado, sem ficar frustrada com isso" e, sobretudo, que este objeto, por falta de usabilidade, não machuque o usuário durante o uso.

Vários são os casos em que o usuário se machuca, ou, no extremo, até morre, por falta de usabilidade: dedos decepados, em um caso recente da indústria automobilística brasileira; e dezenas de mortos, em caso recente da indústria aérea brasileira.

Neste contexto, o design adquire um papel importante, na medida em que ajuda a gerenciar a complexidade, e a construir objetos cujas funções sejam estruturadas, entendíveis, e que ajudem o usuário a realizar a tarefa desejada sem se machucar. Um sistema que, por falta de informação, de usabilidade, entre outros elementos, machuca o usuário, está em violação direta da cidadania deste usuário.

No Brasil, A Constituição de 1988 estabelece, no artigo $6^{\circ}$, que "são direitos sociais a educação, a saúde, o trabalho, a moradia, o lazer, a segurança, (...)”.

Por sua vez, o Código de Defesa do Consumidor (CDC, 1990), prevê como direito básico a proteção à vida, e à segurança contra 
produtos ou serviços considerados perigosos ou nocivos. O CDC exige, também, que o fabricante informe, de maneira ampla e clara, os casos de periculosidades (que devem ser corrigidos) e uso correto do produto. Cabe ao fabricante a responsabilidade pelos danos causados por seus produtos.

Este estudo faz uma reflexão a respeito dos aspectos entre uso e design dos novos produtos com o intuito de identificar os problemas atuais de usabilidade que machucam o usuário. Pretende-se, com esta análise, ajudar os profissionais a gerenciar a complexidade dos produtos, produzindo elementos de design adequados. Dessa forma, realiza-se um levantamento de oito casos, usando a Técnica de Incidente Crítico, identificando as instâncias em que a falta de usabilidade causou um acidente. Finalmente, analisa-se como os princípios de design de usabilidade podem ajudar a construir objetos que apresentem usabilidade satisfatória e segurança no seu uso.

\section{DESIGNS RUINS DE SISTEMAS ESTÃO MATANDO PESSOAS}

Uma das características da sociedade pósindustrial é o advento de inúmeros sistemas de informação, objetos, ferramentas, etc. desenvolvidos a partir do progresso tecnológico, e que foram incorporados no cotidiano das pessoas (NORMAN, 2008). Quando falamos de sistema, contudo, não estamos nos limitando ao computador, ao software, mas a uma gama ampla de objetos, designs e ferramentas.

Observe que o que nos interessa é a interação do ser humano com um sistema para realização de uma tarefa. Com este objetivo, o design a que iremos nos referir pode ser o de uma simples embalagem (destas de alimentos caseiros, por exemplo, que causam transtornos pela dificuldade de serem abertas) até sistemas computacionais mais sofisticados como, por exemplo, os sistemas para controle de trafego aéreo (KRUG, 2006).

Se o usuário não consegue abrir a embalagem de maneira adequada (como é o caso de embalagens de vários produtos alimentícios), então, pode ser o caso de termos o usuário se deparando com um problema de usabilidade provocado pelo design errado. Os sistemas devem ser feitos para facilitar, e não para atrapalhar a vida do usuário. Sobretudo, não devem machucar o usuário.

Segundo PAC (2004), em 2001, a Comissão de Segurança de Produtos de Consumo, órgão oficial do governo norteamericano, divulgou uma estatística revelando que, naquele ano, mais de 4 mil pessoas morreram e mais de 4 milhões de usuários se machucaram por consequiência dos chamados acidentes de consumo, acarretando um gasto aproximado de 300 milhões de dólares por ano.

Para Jorge (2004), acidentes de consumo acontecem quando um produto ou serviço prestado provoca dano à saúde ou à segurança do consumidor, seja esse dano causado por um simples defeito ou pela falta de informação quanto à periculosidade e quanto ao uso correto do produto. Observe que estes conceitos são caros à usabilidade.

O Brasil não apresenta estatísticas nesta área. O PAC (2004), uma parceria da Associação Médica Brasileira e da Associação Brasileira de Defesa do Consumidor realizou um estudo detalhado de acidentes de consumo. O estudo foi feito com 2021 casos de atendimentos de acidentes causados por produtos (embalagens, etc.) e serviços (transporte, etc.) ocorridos em 5 hospitais participantes. O estudo, contudo, não verificou se a falta de conceitos de usabilidade influenciou no acidente. O estudo ressalta, porém, que $73 \%$ dos acidentes estudados ocorrem em função da utilização do produto e/ou serviço. Sendo que $62 \%$ dos acidentes causados por serviços atingiram membros inferiores e superiores. Os acidentes causados por produtos 
atingiram o organismo como um todo, principalmente cabeça/pescoço e sistema gastrintestinal. E $83 \%$ dos acidentes acontecem em casa.

Embora não se tenha, no Brasil, dados estatísticos sobre o assunto, exemplos não faltam: em novembro de 2006, um avião da empresa Gol colidiu com um jato da Legacy, matando pelo menos 155 pessoas. Segundo os controladores de vôo, o sistema apresenta zonas "cegas" (em que os vôos não são monitorados), e, acrescentam: "o software usado na torre de controle teria dado a informação errada de que o Legacyse encontrava a 37 mil pés, quando na verdade estava a 36 mil - em rota de colisão com o Boeing." (ON, 2006).

Em julho de 2007, um acidente com um vôo da empresa TAM teve um total de 199 vítimas. As causas do acidente ainda estão sendo investigadas, mas, segundo Tavares (2008)

\begin{abstract}
"no dia 24 de Julho de 2007, a fabricante da aeronave Airbus divulgou um documento sobre a posição correta do manete quando o reverso estiver travado (desativado), explicando que deve ser utilizado em ponto morto durante o pouso. $O$ alerta do fabricante associado aos acidentes repetidos manifestaria um problema de usabilidade disfarçado de erro humano, posto que, apesar de dispor de um sistema computacional altamente sofisticado, este ainda não alertaria o piloto quando há uma disparidade tal como ocorre quando as turbinas atuam de forma completamente contrárias." (TAVARES, 2008)
\end{abstract}

Em 2008, no Brasil, pelo menos 22 usuários do modelo de automóvel Fox, da Volkswagen tiveram seus dedos decepados ao tentarem manipular o banco traseiro - uma operação que deveria ser simples, mas que acabou machucando o usuário. Segundo o site NA (2008)

"A Volkswagen deveria fazer um recall, de acordo com afirmação de uma advogada(...). Mas a montadora alemã afirma que não existe necessidade, pois os passos para rebater o banco estão descritos no manual. Ou seja, se você rebateu o banco de maneira errada, o problema é seu. Engenheiros e especialistas dizem que na verdade esse problema é causado por um erro grave de projeto, pois o sistema induz a pessoa a botar o dedo ali, sem avisos de que isso seria perigoso.E mais uma vez, como nós e nossos leitores sempre falamos: o consumidor brasileiro não vale tanto para as montadoras quanto um americano ou europeu. Por quê?? Porque no caso do Fox que é exportado para a Europa, no lugar da alça e da argola, há uma alavanca de metal paralela à base”. (NA, 2008)

Thimbleby (2008) reporta dois casos de mortes por erros de usabilidade no uso de sistemas de administração de medicamentos, mais especificamente na forma de entrar com as dosagens, o que fez com que a dose administrada fosse errada por fatores de 10. Canada (2007) reporta duas mortes também causadas por erros de usabilidade de decimais: $5 \mathrm{mg}$ de morfina foram usadas ao invés das corretas $0,5 \mathrm{mg}$. Estes erros ocorreram apesar das agências de saúde destes países terem regras claras sobre como escrever e calcular doses de remédios (como por exemplo: sempre escrever frações com o zero inicial como $0,2 \mathrm{mg}$, e nunca com o zero decimal, como 1 ao invés de 1,0 - que pode ser lido como 10 - escrever mililitros como $\mathrm{mL}$ e não $\mathrm{ml}$, que pode ser confundido com $\mathrm{m} 1$ ). Canadá (2007) mostrou que 3 em 5 enfermeiras ficavam "parcialmente ou completamente" confusas com teclados e decimais.

Todas estas mortes foram causadas por problemas de usabilidade, e poderiam ter sido evitadas. Para Thimblebly (2007 a,b), o problema ocorreu na programação de interação, termo introduzido pelo autor para distinguir os aspectos da interação dos aspectos humanos. Segundo o autor, além de fatores humanos, design e processos centrados no usuário escondem detalhes de como os objetos são operados: fonte potencial de problemas de usabilidade, difíceis de serem detectados, e que podem ter consequiências fatais. Thimblebly (2008) advoga que, embora métodos centrados no usuário sejam essenciais, eles não garantem 
interações seguras, e que estas devem ser obtidas por métodos rigorosos e formais e programação de interação.

Nos problemas médicos citados, os erros ocorreram por que o dispositivo exigia que o próprio usuário realizasse a parte mais difícil da tarefa: calcular a dosagem. Dessa forma, o modelo mental do usuário foi obrigado a seguir o modelo mental do processo, composto de sequiências de teclas. Esta atividade é, de fato, uma "compilação" do problema para o uso na calculadora, o que é uma tarefa difícil (THIMBLEBY, 2000) e que poderia ser evitada se o sistema fizesse esta operação pelo usuário.

\section{Os Problemas e Princífios de Design}

O desenvolvimento de sistemas deve ser metódico. Muitas vezes as coisas saem de controle. Os resultados, então, insultam a nossa inteligência, impedem os nossos objetivos e acabam com o nosso humor. Quando consideramos o porquê dos sistemas de hoje serem difíceis de aprender, estranhos de usar, mudam as nossas tarefas de maneiras que não desejamos, a resposta pode estar no processo, sobre o qual se fala como se fosse ciência, mas é praticado sem método. Os sistemas são ruins porque são mal projetados. Existem boas idéias e habilidades técnicas, mas estas são atrapalhadas pela confusão, pelas interações erradas, pela falta de cuidados com o processo, e o conjunto, então, fica simplesmente terrível. (CARROLL, 1995).

Design não é um tipo de resolução de problema que seja simples ou rotineiro. Reitman (1965) discute algumas propriedades de problemas de design, principalmente para mostrar que, embora sejam tipos de problemas mais importantes e menos estruturados que outras categorias de problemas, poucos são os estudos que se dedicam ao design e à resolução de seus problemas; principalmente se comparados a estudos de problemas menos complexos.

Inicialmente, $\mathrm{o}$ autor aponta que as situações de design quase nunca são completamente específicas em suas condições de partida. Como em todo problema de análise, o primeiro passo, e talvez o mais difícil, seja identificar, claramente, uma descrição relevante da situação atual que deva ser alterada pelo trabalho do design. Muitas vezes, a descrição da situação atual, que direciona o design, não é completa, não é correta ou é irrelevante.

Uma segunda dificuldade característica de problemas de design é o passo que o designer pode ou deve dar no sentido de melhorar um sistema, que, para começo de conversa, nem mesmo está bem especificado. $\mathrm{O}$ designer então segue escolhendo uma direção e verificando as consequiências. Se a conseqüência não for a desejável, deve-se rever a escolha, entendê-la, reestruturá-la e testar um novo passo. Porém, nem sempre é isso que ocorre: uma vez tomada uma decisão, ou o designer não acompanha o seu desenrolar, para observar as suas falhas e conseqüências, ou tendem a transferir para o usuário a responsabilidade pelo problema decorrente dessa decisão.

Adicionalmente, os problemas de design quase nunca especificam os objetivos ou solução final. Podemos saber dos problemas que se apresentam, mas talvez não tenhamos idéia de como conseguir uma melhoria. Sob este ponto de vista, pode-se dizer que quando um estado final de solução é especificado, o trabalho de design pode estar completo, o que nem sempre é verdade.

\section{Os Problemas e Princípios de USABILIDADE}

O sucesso de aceitação de um sistema de informação, aí incluídos objetos de uso cotidianos, é diretamente proporcional à sua interação e integração com o ambiente social onde se encontra (OLIVEIRA, 2003). 
Dentro da área de interação homemmáquina, Sorj (2003) aponta a necessidade de que essas novas tecnologias tenham boa usabilidade nas tarefas demandadas pelos seres humanos, a fim de que o serviço ali oferecido seja socialmente aceito, promovendo qualidade de vida e integração social para os seus usuários.

A usabilidade se efetiva no sistema quando esse permite que os usuários consigam, com facilidade, alcançar e executar seus objetivos. Para Carroll e Moran (1996), a facilidade no momento do uso, percepção e recuperações dos erros, compreensão facilitada para utilizar o sistema, ao executar uma tarefa, e sucesso nessas execuções são características principais, necessárias para que um sistema apresente boa usabilidade. Dessa forma, quando um sistema não apresenta usabilidade, surgem problemas, pois os usuários terão dificuldades em realizar suas tarefas com sucesso, podendo até mesmo resultar em fracasso na aceitação do mesmo pela sociedade. A falta de usabilidade, hoje, é um dos maiores problemas encontrados nos designs de objetos (GUIMARÃES, 2008).

Se o design não apresentar facilidade de uso satisfatória, os sistemas podem fracassar em vários aspectos, causando transtornos. Enfim, a implementação de qualquer tecnologia da informação deve ter o ser humano como foco principal. A falta de usabilidade impede o acesso à informação, impede o uso correto, e pode acarretar acidentes. A medida do sucesso do design encontra-se na satisfação do usuário usando a ferramenta, de maneira eficaz e eficiente, para realizar suas tarefas sem machucar o usuário (CARROL, 1995).

Realizou-se, no dia 06 de maio, em São Paulo, o Seminário Internacional sobre Consumo Seguro, patrocinado pela Associação Brasileira de Defesa do Consumidor Pro Teste. Entre outras coisas, o seminário concluiu que, mesmo seguindo as normas nacionais, os produtos não alcançam a segurança mínima, e foi citado o exemplo do carro Fox, da Volks, cujo modelo europeu recebeu quatro estrelas, mas quando foi avaliado na Europa, recebeu apenas uma estrela e meia. Donald L. Mays, da Consumers Union, que tem 4,2 milhões de assinantes, possui 52 laboratórios e registra uma média de 3.500 produtos testados por ano, diz que: "teste é o foco. Temos tabelas de classificação por desempenho, por segurança, por facilidade de uso. E os relatórios são colocados nos blogs." Juan Trimboli, diretor para a América Latina da Consumers International, que reúne 230 entidades nos cinco continentes, lembra que estas informações são importantes, pois: "A área de consumo é um exercício de cidadania. Cidadão econômico é aquele capaz de participar, decidir, influenciar. E não são todos os que podem participar por causa da exclusão social." (O GLOBO, 2009).

A tendência crescente de se embutir software em produtos físicos aumenta o risco de acidentes, especialmente em softwares médicos, que podem salvar vidas, mas também matar (ROCKOFF, 2008). Problemas de software exigiram reparos em 200.000 aparelhos para o coração entre 2000 e 2009 nos Estados Unidos (MAISOL et al, 2001). A agência FDA (Food and Drug Administration - administração de comida e drogas) registrou, de 1985 a 2005 , 30.000 mortes e 600.000 acidentes, com aproximadamente $8 \%$ atribuídos ao software (FDA 2006). Contudo, como apenas 1 em 40 dos acidentes são reportados, este percentual é certamente muito maior (GAO 1986).

\section{ALgUMAS VARIÁVEIS DE ANÁLISE E CORREÇÃO DE PROBLEMAS}

Affordance (do Inglês, to afford, pode ser entendido como "ter condições de", "é para") é um termo que se refere à capacidade do objeto de passar ao usuário as funções que o usuário tem condições de realizar com aquele objeto. Assim, o objeto "dá uma pista" de como funciona (NORMAN, 1999). 
Quando usado neste sentido, o termo se refere às propriedades atuais e percebidas de um objeto, principalmente aquelas propriedades fundamentais que determinam exatamente como este objeto pode possivelmente ser usado. Estas propriedades, inerentes do design do objeto, indicam a forma de uso, as funções que podem ser executadas, as tarefas para as quais são adequadas, etc. Um martelo, por exemplo, não é a melhor ferramenta para se usar quando se tem um parafuso. Contudo, ao ser observado, o cabo sugere o lado em que se segura a ferramenta; na parte de metal, a cabeça indica que aquela é a parte usada para bater o prego.

Quanto à visibilidade, para executar as suas tarefas, o usuário necessita de que os elementos que ele vai usar estejam claramente visíveis, como devem ser usados, qual função executam, etc. O usuário tem que encontrar no sistema elementos que reproduzam, fisicamente, as ações pretendidas.

Problemas de falta de affordance e de visibilidade são comuns nos sistemas: Quantas vezes já pegamos um objeto e não conseguimos identificar as suas partes e funções? Uma porta que não indica se devemos puxar ou empurrar? Uma maçaneta de um carro: puxar, girar? Um bom design, que leva estes conceitos em consideração, torna os sistemas fáceis de ser entendidos e usados. Um design errado, por outro lado, pode impedir o usuário de realizar a tarefa pretendida.

Guimarães (2008) sugere formas de mitigar estes problemas de design: "Clarificação do problema. Requisitos de design. Identificação de opções. Visualização das soluções. Reconhecendo as escolhas e dependências. Integrando conhecimentos e habilidades diversas. Antecipação do impacto nas atividades humanas.".

Schön (1967), ao discutir as mudanças trazidas pela tecnologia, argumenta que temos que lutar contra a tendência de tomar o caminho mais fácil, ou seja, de simplificar e idealizar soluções "simplistas", que nos são familiares, mas que podem não ser as adequadas: devemos combater a nossa tendência a adotar, rapidamente, a primeira alternativa que se apresenta.

Para Norman (2008), a minimização de complexidade pode ser obtida usando regras simples: modularização, mapeamento e modelos conceituais. $\mathrm{O}$ autor entende modularização como sendo a divisão de uma tarefa em módulos menores, mais fáceis, em que cada função é agrupada, tornando-se simples. Somente os controles necessários à realização da tarefa devem ser apresentados e realçados. Bom mapeamento é importante para que seja aparente o relacionamento entre a ação e o resultando obtido em função desta ação, principalmente na percepção da realização do objetivo desejado. Um bom modelo conceitual apresenta ao usuário como as coisas devem ser feitas, o quê está acontecendo e o que se deve esperar. Isto inclui um bom "feedback".

Norman (2008) conclui que:

"O argumento não é entre funções e simplicidade e usabilidade. O problema real é com o design: fazer o design dos objetos que tenham a potência e funcionalidade requeridas para executar a tarefa, e mantendo, ao mesmo tempo, a inteligibilidade, a sensação de controle $e$ o prazer de realização".

Norman e Draper (NORMAN, 1988) concentraram seus estudos em aplicar a ciência ao design de sistemas. Os autores partiram das diferenças entre os objetivos e intenções do usuário, que são variáveis psicológicas, e os aspectos físicos do sistema a ser usado para a realização do objetivo. O usuário analisa e dá significado ao sistema em função da tarefa a ser realizado. Isto significa que, em algum estágio, existe uma "tradução" entre os dois aspectos, o psicológico e o físico.

Segundo os autores, o usuário encontrará dificuldades em realizar uma tarefa quando www.unibh.br/revistas/exacta 1 v. 2, n. 1, jun 2009 
houver discrepâncias entre o seu modelo mental e o modelo do sistema. O usuário cria a intenção de executar uma tarefa e interage com o sistema para atingir o objetivo desejado, planejando as ações a serem executadas. Este mapeamento entre intenção e ações físicas a serem executadas no sistema é o primeiro passo de design.

Em seguida os autores elencam sete estágios de atividades que ocorrem na interação, desde a intenção até o entendimento (ou não) de que a tarefa foi executada. Um bom design vai dar suporte a estes estágios. Ou seja, o mapeamento entre os objetivos psicológicos e as operações físicas no sistema deve apresentar o mínimo de discrepância possível. O Golfo da Execução é a parte da atividade em que o usuário, com um objetivo a cumprir, parte para realizar a sua tarefa. Ele então forma a intenção, especifica o conjunto de ações que deve seguir e as executa, através de contatos com a interface do sistema. O Golfo da Interpretação ocorre após a execução das ações. O usuário então compara os resultados obtidos no sistema e os compara para determinar se o objetivo inicial foi alcançado.

\section{Pesquisa de Usabilidade}

A presente pesquisa é de caráter exploratório, desenvolvida com o objetivo de proporcionar uma visão geral acerca da falta de usabilidade em designs que ocasionam acidentes nos usuários durante o uso. Este tipo de pesquisa é realizado especialmente quando o tema escolhido é pouco explorado e torna-se difícil sobre ele formular hipóteses precisas e operacionalizáveis. Segundo Ariboni \& Perito (2003), a pesquisa exploratória serve ao propósito de desenvolver, esclarecer e modificar conceitos e idéias, com vistas à formulação de problemas de estudo mais precisos ou hipóteses pesquisáveis para estudos posteriores. Dessa forma, como indicado em seções anteriores, este trabalho visa ajudar os desenvolvedores e a indústria a fazerem produtos melhores, que sigam a teoria de fatores humanos e usabilidade, incluindo o desenvolvimento de sistemas, de quaisquer tipos, que não machuquem o usuário.

Sob um ponto de vista mais abrangente, a finalidade é iniciar uma reflexão mais séria e profunda a respeito dos problemas causados pela falta de usabilidade e contribuir na solução destes problemas através de sugestões sucintas de melhoria. A metodologia baseia-se na exposição de alguns casos de acidentes relativamente comuns para muitas pessoas, explicar formalmente o motivo e sugerir melhorias para o produto. É importante ressaltar que a metodologia não precisa formalizar dados estatísticos, pois quando uma pessoa se machuca ao utilizar um produto já é o suficiente para que o ocorrido seja identificado como um grave problema de usabilidade. Os resultados advindos do estudo desse tipo de situação podem nos fornecer um conhecimento maior sobre a relação entre a falta de usabilidade e as instâncias em que esta falta, machuca o usuário durante o uso. Com base no referencial teórico, procurou-se:

- Identificar as instâncias em que a falta de usabilidade de objetos machucou o usuário;

- Identificar as teorias de usabilidade que foram negligenciadas no design destes objetos;

- Identificar possíveis soluções para os problemas levantados, à luz do referencial teórico;

- Alertar a comunidade a respeito deste grave problema.

A pesquisa foi realizada com sete estudantes universitários de graduação e pósgraduação de informática. Todos os pesquisados já haviam cursado as disciplinas de Usabilidade e Interação Humano-Computador. Foi usada, como instrumento de coleta de dados, a Técnica de Incidente Crítico (CIT) que define um conjunto de procedimentos adaptados a uma metodologia de estudo e referencial teórico utilizados para suprir a demanda de uma 
determinada pesquisa (GUIMARÃES, 2007). Ainda segundo Guimarães (2007), essa técnica pode ser utilizada para mapear o entendimento do comportamento humano na resolução de problemas como, por exemplo, requisitos de sistemas, mostrando grande utilidade ao se estudar o perfil dos usuários e o uso que estes fazem da informação. Com isso, foi solicitado a cada participante que relatasse:

“(...) uma situação de uso de um sistema de informação, um objeto, uma embalagem, um design, enfim, uma ferramenta, que, ao ser usada para a realização de uma determinada tarefa, tenha apresentado alguma falha de usabilidade. Relate o caso em que esta falha tenha tido como conseqüência um acidente que tenha machucado o usuário."

Os casos relatados foram analisados conforme se apresenta a seguir.

\section{ReSultados e Análises - A Falta de DESIGN DE USABILIDADE MACHUCANDO AS PeSSOAS}

A seguir são descritos oito exemplos de sistemas que, por falta de usabilidade, causam acidentes durante o seu uso. Estes problemas podem e devem ser evitados. As análises procuram mostrar alguns pontos teóricos das causas dos problemas e apresentar as respectivas sugestões de solução.

\subsection{Caso 1: Problema Com barRa de APOIO DO ÔNIBUS}

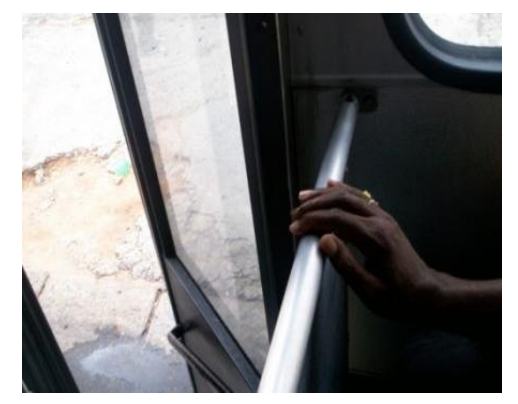

Figura 1: Barra de Apoio do Ônibus

Foram relatados casos de usuários do transporte coletivo que tiveram suas mãos prensadas pela porta do ônibus enquanto seguravam na barra de apoio próxima à porta, conforme apresentado na Figura 1. Analisando o ocorrido foi possível constatar que estes acidentes são frutos de problemas de affordance e visibilidade, pois a barra de apoio do ônibus proporciona o affordance de ser útil para que o usuário se valha dela para se firmar no ônibus, para isso o usuário segura na barra, porque esta é a visibilidade que a mesma oferece. Entretanto ao realizar esta ação o usuário acaba se ferindo, pois a distância entre a barra e a porta é muito curta, logo quando a porta está sendo aberta, esta distancia fica ainda menor, e a mão do passageiro acaba sendo prensada. Portanto duas análises podem ser feitas:

- Ou a barra não deve ser utilizada para apoio dos passageiros, devendo então ser retirada ou mesmo substituída por outro elemento que não tenha este affordance.

- Ou então a usabilidade da barra de apoio deve ser corrigida de modo a garantir a segurança física dos usuários, isto pode ser feito aumentando a distância entre a barra e a porta.

\subsection{Caso 2: Problemas Com SaChe de Catchup}

Foi relatado um caso de um rapaz que quebrou um dente ao tentar abrir o sache de catchup com os dentes, como mostrado na Figura 2. Analisando o acidente constatamos que sua principal causa foi o design errado do sache que oferece a visibilidade que o mesmo deve ser aberto rasgando a embalagem com as mãos. Entretanto, na maioria dos casos, por mais força que se empregue, não é possível abrir o sache da forma indicada. Adicionalmente, invariavelmente, uma das mãos está ocupada, segurando o sanduíche. Logo as pessoas burlam o sistema e tentam rasgá-lo com os dentes, tornando propício assim a ocorrência de acidentes como o descrito. Portanto este 
problema poderia ser claramente solucionado através da correção do design do sache que deveria facilitar sua abertura.

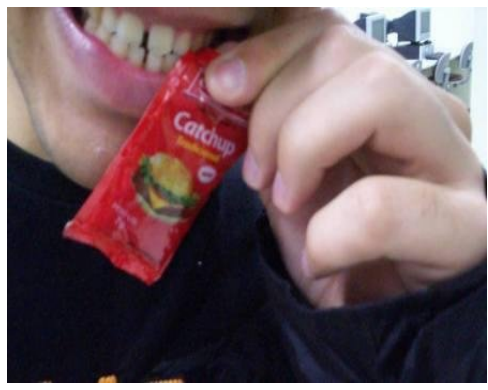

Figura 2: Sache de Catchup

\subsection{CASO 3: Problema COM ARMÁRIO}

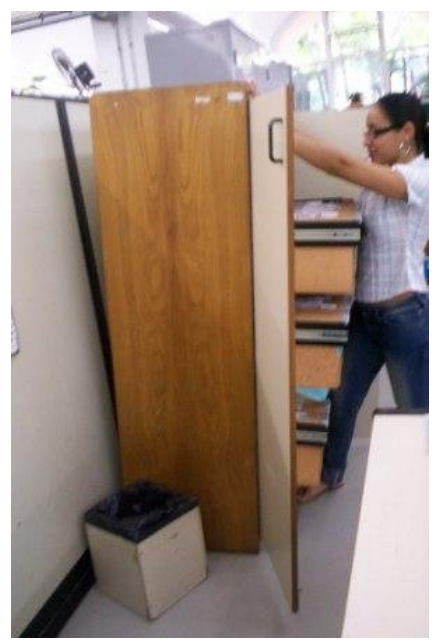

Figura 3: Armário

O problema relatado neste caso foi de um armário que tombou sobre uma funcionária pública quando esta estava abrindo as gavetas do armário. Este fato ocorreu porque mais uma vez o design do produto era inadequado, pois o armário possui várias gavetas, entretanto ele não suporta o peso de mais de uma gaveta aberta simultaneamente. Logo, quando este fato ocorre, o peso do armário faz com que ele caia para frente, ferindo o usuário. Enfim, o sistema permite ao usuário realizar o objetivo desejado de abrir mais de uma gaveta. Contudo, esta ação não corresponde à capacidade do sistema, que tomba com o peso das gavetas abertas. Analisamos duas possíveis soluções para corrigir este problema de design do armário:

- Criar um dispositivo no armário que impeça que mais de uma gaveta seja aberta simultaneamente;

- Ou criar o armário com materiais que suportem o peso de varias gavetas abertas concomitantemente.

\subsection{CASo 4: Problemas COM ISQUeIRo}

Um rapaz quando foi acender seu cigarro com um isqueiro queimou uma parte de seu rosto e sua sobrancelha com a chama. Constatamos que este acidente foi causado por que o isqueiro apresentava problemas de visibilidade, pois são bem visíveis o botão de acionar a chama e o local de onde sai a chama. Porém, o botão responsável pela regulagem do nível da chama não possui boa visibilidade. Então, ao se acionar o acendimento da chama do isqueiro, por vezes, é totalmente ignorado o nível que está regulado a chama. No caso em questão, a chama estava muitíssimo alta, e, como o isqueiro estava sendo usado para acender um cigarro que estava na boca do usuário, a chama acabou queimando o rosto do mesmo. Este fato poderia ser evitado se a visibilidade do botão de regulagem da chama fosse aumentada, ou então se houvesse um mecanismo de trava/segurança no isqueiro para limitar o seu acendimento com chamas muito altas que pudesse propiciar situações de perigo de lesão ao usuário.

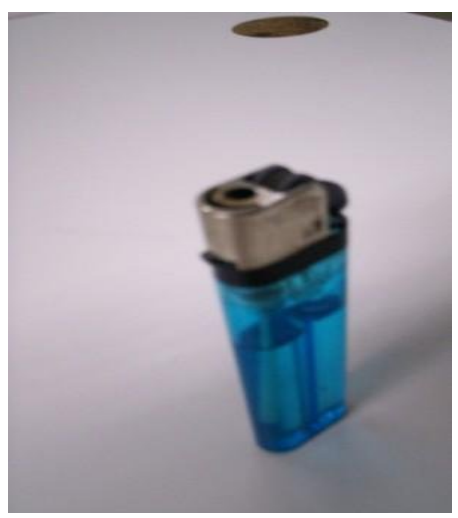

Figura 4: Isqueiro \begin{tabular}{l|l|l|l} 
e-xacta & Belo Horizonte & ISSN 1984-3151 & www.unibh.br/revistas/exacta
\end{tabular} 


\subsection{Caso 5: Problemas Com latas de SARDINHA}

São vários os relatos de pessoas que feriram suas mãos ao abrirem as latas de sardinha ou atum. A visibilidade de como a lata deve ser aberta é satisfatória, entretanto o design da lata é incorreto, pois as extremidades da "tampa" e da abertura da lata são extremamente cortantes. Quando os usuários tentam abrir ou tentam tirar o alimento de dentro da lata eles acabam esbarrando nestas extremidades e, assim, acabam cortando suas mãos. A correção deste problema poderia ser feita mudando o design da lata. Por exemplo, a lata teria uma tampa de encaixe, logo não seria necessário cortar o metal da lata para abri-la, sem partes cortantes na lata que pudessem ferir as pessoas.

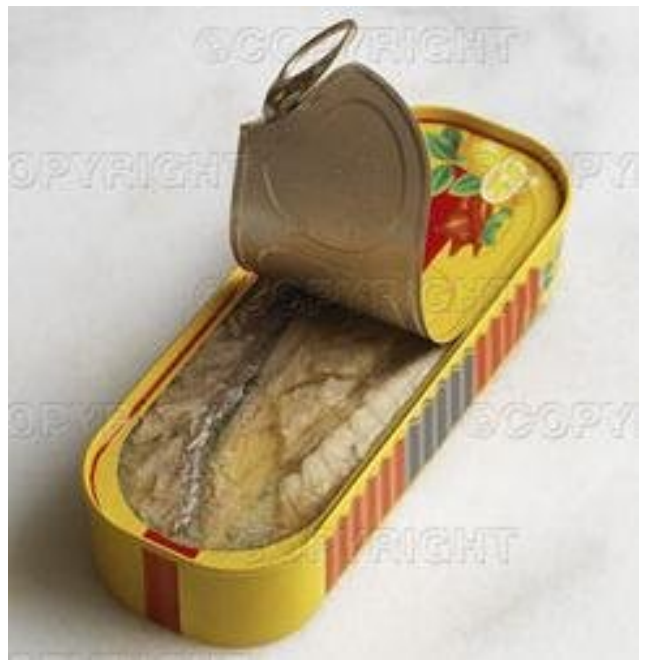

Figura 5: Lata de sardinha

\subsection{CASO 6: Problemas COM FicháRIO ESCOLAR}

É comum encontrar pessoas, principalmente estudantes, que já tenham machucado as mãos ao tentar fechar as presilhas de um fichário escolar. Estas presilhas costumam prender perfurando os dedos dos usuários que tentam fechá-las, exigindo deles muito cuidado. Existe um distanciamento entre o mapeamento do que o usuário deseja e o elemento que o sistema oferece para executar a ação, ocasionando falha no golfo de execução. Uma sugestão para resolver este tipo de problema é fornecer um elemento com affordance e visibilidade que possibilite ao usuário executar a ação: abrir e fechar as presilhas com segurança.

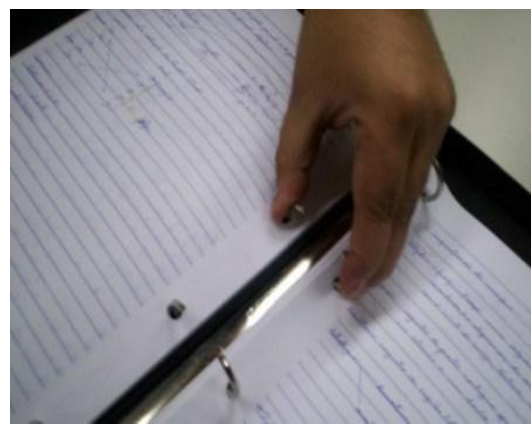

Figura 6: Fichário escolar

7.7 CASo 7: Problemas COM CHAVE DE RODA

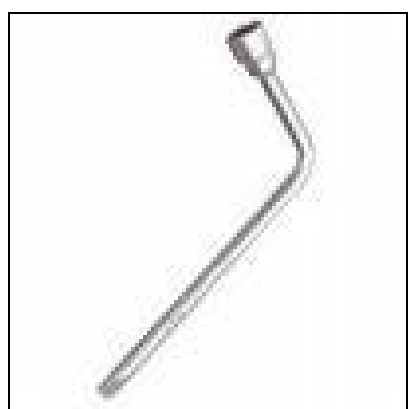

Figura 7: Chave de roda

Neste caso, o problema relata a situação do usuário que, por falta de alavanca, subiu na chave de roda para aplicar mais peso a fim de conseguir tirar os parafusos da roda do carro: a ferramenta soltou-se e perfurou a perna do usuário. Na falta de alavanca, o usuário burla o sistema, se utilizando da visibilidade que a ferramenta apresenta para ele pisar em cima e obter mais força, atingindo assim o objetivo. Ocorre aqui falha no golfo de execução. Para solucionar este problema, sugere-se a produção de uma ferramenta que apresente uma alavanca maior, mas que seja retrátil para atender as exigências de portabilidade. 


\subsection{Caso 8: Problemas com basculante DO ÔNIBUS}

O problema aqui especifica que um usuário, ao tentar fechar o basculante, cortou as mãos nas barras de movimento do mesmo. O elemento de design apresentado para executar a tarefa de fechar o basculante não é suficiente. Para executar a tarefa, o usuário burla o sistema se valendo da visibilidade dos eixos de movimento do basculante. A solução para este problema pode ser criar um dispositivo automático que realize a tarefa sem necessidade de força adicional.

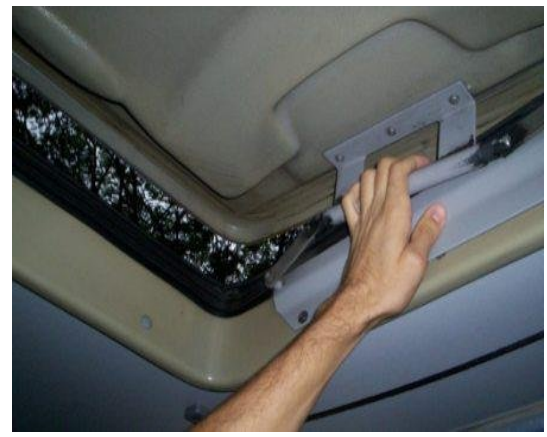

Figura 8: Basculante do ônibus

\section{CONCLUSÃo}

Atualmente, percebem-se diversos sistemas que devem ser analisados quanto às orientações de manuseio, pois a quantidade destes produtos cresce exponencialmente conforme a demanda criada pela sociedade e, quanto mais pessoas, mais perfis diferentes são encontrados. $\mathrm{Na}$ urgência da produção em escala, da produtividade da equipe de desenvolvimento ou, até mesmo, por causa das regras de negócio estabelecidas, os produtos não são construídos de forma muito sistemática e o design ali associado é considerado apenas como um assessório de apresentação. Embora difícil, o processo de design pode e deve ser seguido, principalmente quanto à averiguação das conseqüências de seu uso. Neste sentido, deve garantir a construção de sistemas que apresentem usabilidade e, sobretudo, que não machuquem o usuário.

Além dos exemplos apresentados, este estudo mostrou oito casos em que, por falta de usabilidade, os usuários se machucaram durante o uso. Os sistemas não podem machucar seus usuários e os designers devem ser responsabilizados por este problema, pois a literatura referente às áreas de IHC estuda as ações dos fatores humanos na usabilidade de produtos e sistemas. Dessa forma, já que o design é um dos fatores abordados dentro do estudo sobre usabilidade, o profissional correspondente deve possuir a consciência de que estudos mais completos e universais devem ser feitos; que as informações devem ser amplamente divulgadas ao usuário, para que ele saiba que a responsabilidade é do designer; e que séries estatísticas devem ser mantidas.

\section{Agradecimentos}

Os autores agradecem a oportunidade dada pelo Centro Universitário de Belo Horizonte para a publicação deste trabalho como, também, o ato de difundir o conhecimento. Agradecem também ao orientador e professor Cayley Guimarães pelo apoio e incentivo, e ao empenho de todos que ajudaram para a realização deste estudo.

\section{REFERÊNCIAS}

ARIBONI, S., PERITO, R. (2003) “Guia prático para um projeto de pesquisa - exploratória, experimental, descritiva." São Paulo: UNIMARCO.

CANADA (2007). Canada Institute for Safe Medication Practices. "Fluorouracil Incident Root Cause Analysis." Disponível em www.ismp-canada.org acessado em 05/11/2008.

CARROLL， J.M. (1995). "Scenario-Based Design: Envisionig work and Technology in System Developments." New York: John Wiley \& Sons. \begin{tabular}{l|l|l|l} 
e-xacta & Belo Horizonte & ISSN 1984-3151 & www.unibh.br/revistas/exacta
\end{tabular} v. 2, n. 1, jun 2009 
CARROLL, J. M. e MORAN, T. P. (1996), "Desing Rationale: concepts, techniques, and use". New Jersey: LEA.

CDC (1990) "Código de Defesa do Consumidor" L-008.078-1990 disponível em http://www.mj.gov.br/dpdc/data/Pages/MJ7E3E

5AAEITEMID506CB3D5B5C440F795E975090 95C851EPTBRIE.htm acessado em 01/12/2008

FAD. (2006) "Ensuring the safety of marketed medical devices: CDFH's medical device postmarket safety program. In Jackson, D. "A direct path to dependable software". (2009). Communications of the ACM. V. 52, n.4. pp. 78-88.

GAO. (1986) "Medical Devices: Early warning of problems is hampered by severe underreporting." Publication PEMF-87-1, U.S. Government Printing Office. In Jackson, D. "A direct path to dependable software". (2009). Communications of the ACM. V. 52, n.4. pp. 78-88.

GUIMARÃES, C. (2007). "Técnica de Incidente Crítico - Pesquisa de uso da Informação". Londrina: II SECIN - Seminário de Ciência da Informação.

GUIMARÃES, C. (2008), "Usabilidade no diaa-dia: A interação de seres humanos e sistemas", Belo Horizonte: Fundac Editora.

JORGE, MARCOS (2004) "O perigo nos produtos e serviços". Espaço Aberto, n.54 disponível em http://www.usp.br/espacoaberto/ arquivo/2004/espaco45jul/0comportamento acessado em 01/12/2008.

KRUG, Steve. (2006), "Não me faça pensar". Rio de Janeiro: Alta Books.

NORMAN, D. A. (1988). "The Psychology of Everyday Things." New York: Basic Books. (Reissued in 1989 as The Design of Everyday Things. New York: Doubleday.)
NORMAN, D.A. (2008) "Simplicity is not the Answer". ACM: Interactions. V. XV.5, pp. 4546.

OLIVEIRA, J. P. M. (2003), "Sistemas de Informação e Sociedade", In Ciência e Cultura. Disponibilizada em http://cienciaecultura.bvs.br/ scielo.php?script=sci_arttext\&pid=S0009-67252 $003000200023 \& \operatorname{lng}=$ pt\&nrm $=$ isso acessado em 06/09/2008.

ON (2006) OPINIÃO E NOTÍCIA "Controladores falam do acidente entre Boeing da Gol e Legacy, pela primeira vez" disponível em http://opiniaoenoticia.com.br/interna.php?id= $\underline{6811}$ acessado em 01/12/2008.

NA (2008) NOTÍCIAS AUTOMOTÍVAS "Volkswagen Fox decepa os dedos de seus donos!". Disponível em http://www.noticiasauto motivas.com.br/volkswagen-fox-decepa-o-dedode-seus-donos/ acessado em 01/12/2008.

PAC. (2004) "Acidentes de Consumo Mobilização e prioridades para defesa do consumidor". Disponível em http://www.crianca segura.org.br/downloads/pesquisa/Apresentacao \%209.pdf acessado em 01/12/2008.

REITMAN, W. (1965) "Cognition and thought: An information processing approach." New York: John Wiley and Sons.

ROCKOFF, J. (2008) "Flaws in medical coding can kill: Spread of comuters creates new dangers, FDA officials warn". In Jackson, D. "A direct path to dependable software". (2009). Communications of the ACM. V. 52, n.4. pp. 78-88.

O GLOBO (2009) "Produto Seguro, uma realidade ainda distante - Especialistas dizem que testes fazem com que as empresas melhorem a segurança de mercadorias". In Sampaio, Nadja, Col. Defesa do Consumidor, Caderno Economia, Domingo, 10 de maio de 2009, p. 30. 
SCHÖN, D.A. (1967) “Technology and change: Human-Computer Studies 52, no. 6, pp. 1031The new Heraclitus." New York: Pergmon 1069.

Press.

THIMBLEBY, H. (2007a) "Press on: Principles

SORJ, B. (2003), “Brasil@povo.com”, Rio de Janeiro: Jorge Zahar Editor.

of Interaction Programming." Cambridge: MIT Press.

TAVARES, A. M. M. (2008), “Hoje faz um ano do maior desastre aéreo do Brasil" disponível em http://www.ancomarcio.com/site/publicacao.php ?id=16312 acessado em 02/12/2008.

THIMBLEBY, H. (2007b) "Interaction Walkthrough: Evaluation of Safety Critical Interactive Systems", DSVIS, 4323, p. 52-66.

THIMBLEBY, H. (2008) "Ignorance of THIMBLEBY, H. (2000) "Calculators are Interaction Programming is Killing People." Needlessly Bad". International Journal of ACM: Interactions (sep/oct) v XV.5, pp. 52-57. 